\title{
Correction to: Computational study on hemodynamic changes in patient-specific proximal neck angulation of abdominal aortic aneurysm with time-varying velocity
}

\author{
Yousif A. Algabri ${ }^{1}$ - Sorracha Rookkapan ${ }^{2} \cdot$ Vera Gramigna $^{3}$ - Daniel M. Espino ${ }^{4}$ Surapong Chatpun ${ }^{1}$ (I)
}

Published online: 5 March 2019

(c) Australasian College of Physical Scientists and Engineers in Medicine 2019

\section{Correction to: \\ Australasian Physical \& Engineering Sciences in \\ Medicine \\ https://doi.org/10.1007/s13246-019-00728-7}

The name of the third author was incorrect in the initial online publication. The original article has been corrected.

Publisher's Note Springer Nature remains neutral with regard to jurisdictional claims in published maps and institutional affiliations.

The original article can be found online at https://doi.org/10.1007/ s13246-019-00728-7.

Surapong Chatpun

surapong.c@psu.ac.th

1 Institute of Biomedical Engineering, Faculty of Medicine, Prince of Songkla University, 6th floor, 100-year Building, Hatyai, Songkhla 90110, Thailand

2 Department of Radiology, Faculty of Medicine, Prince of Songkla University, Hatyai, Songkhla 90110, Thailand

3 Neuroscience Research Center, University Magna Graecia, 88100 Catanzaro, Italy

4 Department of Mechanical Engineering, University of Birmingham, Birmingham B15 2TT, UK 